Journal of Universal Language 17-1

March 2016, 81-107

\title{
A Processing Approach to Complex NP Island Effects in Korean
}

\author{
Soo-Yeon $\mathrm{Kim}^{1}$, Sungsoo Ok ${ }^{1}$ \& Jeong-Me Yoon ${ }^{2}$ \\ Sejong University ${ }^{1}$ \& Myongji University ${ }^{2}$
}

\begin{abstract}
Questioning the syntactic assumptions of Island effects on movement operations, this paper investigates, through an acceptability judgment experiment with native Korean speakers, whether wh-in-situ questions in Korean show Complex Noun Phrase (CNP) Islands effects, and if so, what causes them? The
\end{abstract}

\footnotetext{
* This work was supported in part by a National Research Foundation of Korea Grant funded by the Korean government (NRF-2013S1A5A2A01019192) to the first author.
}

Soo-Yeon Kim

Department of English Language and Literature, Sejong University 98 Gunja-dong, Gwangjin-gu, Seoul 143-747, Korea

Phone: +82 23408 3634; Email: kimsy@ sejong.ac.kr

Sungsoo Ok

Department of English Language and Literature, Sejong University

98 Gunja-dong, Gwangjin-gu, Seoul 143-747, Korea

Phone: +82 23408 4471; Email: oss0928@naver.com

Jeong-Me Yoon: Corresponding author Department of English Language and Literature, Myongji University 50-3 Namgajwa-dong, Seodaemun-gu, Seoul, Korea

Phone: +82 2300 0536; Email: jeongme@gmail.com

Received February 15, 2016; Revised March 2, 2016; Accepted March 9, 2016 
82 A Processing Approach to Complex NP Island Effects in Korean

results of the experiment indicate that the acceptability of $w h$-insitu questions with a CNPC violation in Korean shows a wide range of variation and that factors such as distance and referential specificity affect their acceptability. Given that these results cannot be adequately explained by a purely syntactic approach to Islands and that similar facts have been taken as evidence for the processing nature of Island effects in overt wh-movement languages, we interpret them as showing the processing nature of CNP Island effects of $w h$-in-situ questions in Korean. As for the claim that $w h$-in-situ questions in Korean do not show CNP Island effects unlike overt $w h$-movement questions, commonly made and accepted in the syntactic literature, we suggest that the difference in Island effects can arise from the differences in the processing costs of overt wh-movement questions and wh-in-situ questions.

Keywords: Complex NP Constraints, Island Effects, Processing, Gradient Acceptability, Filler-Gap Dependency, Dependency Links, Specificity, D-linking, Distance between a Wh-phrase and a Question Particle

\section{Introduction}

Since Chomsky (1962), Island effects have been considered paradigmatic evidence for movement, playing an important role in developing generative grammar. Despite disputes regarding various approaches to explaining these effects in the framework of generative grammar, it has been generally agreed upon that Islands are effective against movement. In this respect, the standard syntactic assumption about Island effects of $w h$-in-situ questions in Korean has been that they do not show such effects. For instance, unlike the overtly moved $w h$-phrases as in (1), the following sentence with a wh-phrase in the complex noun phrase Island does not seem to show any Complex 
Noun Phrase Constraint (hereafter, CNPC) effects as in (2). ${ }^{1}$

(1) * What did he know [the man that has ] ?

(2) (Ne-nun) [nwu-ka ssu-n chayk]-i caymiiss-ess-ni? (you-Top) [who-Nom wrote]-Rel book-Nom interesting-Past-Q 'Who is the person $\mathrm{x}$ such that the book $\mathrm{x}$ wrote is interesting?'

A closer look, however, reveals that not all $w h$-in-situ questions violating CNPC in Korean are equally acceptable, as we can see in the rather degraded status of the following sentences:

(3)a. ? (Ne-nun) [mwues-ul mantu-nun salam]-ul manna-ss-ni? you-Top what-Acc make-Rel person-Acc meet-past-Q (lit.) 'What is the thing $\mathrm{x}$ that you met a person who made $\mathrm{x}$ ?'

b. ??? (Ne-nun) [nwuka manna-n 1 haknyen 3pan you-Top [who-Nom meet-Rel 1st grade class 3 haksayngtul]-i ttokttokhata-ko sayngkakha-ni? students-Nom smart-Comp think-Q (lit.) 'Who is the person $\mathrm{x}$ that you think [1st grade group 3 students [that $\mathrm{x}$ met]] is smart?'

In fact, some of the sentences violating the CNPC in Korean appear to be quite unacceptable, as we see in (3b). These kinds of

1 The following sentence in Japanese, which does not require overt wh-movement like Korean, is acceptable without showing the CNPC effects, as mentioned in Nishigauchi (1992: 213):

(i) [Dare-ga ti kai-ta honi]-ga omosiroi-desu-ka? who-Nom wrote book-Nom interesting-be-Q

'Who is the person $\mathrm{x}$ such that the book that $\mathrm{x}$ wrote is interesting?' 
less-than-perfect/acceptable instances of CNPC violations have been mostly ignored, either consciously or unconsciously, in the discussion of CNPC effects in Korean, as most syntacticians typically cite good cases such as (2) to show the absence of CNPC effects. Given this state of affairs, an obvious question we should ask is why we should base our claim about the existence or absence of CNPC effects of Korean $w h$-in-situ questions on the acceptability of sentences like (2), rather than on the degraded status of (3), simply concluding that there are no CNPC effects.

Interestingly, the acceptability of overt $w h$-movement questions violating the CNPC also varies considerably from unacceptable to quite acceptable as in the $w h$-in-situ questions in (2) and (3) (Hofmeister \& Sag 2010). ${ }^{2}$

(4) a. I saw which convict Emma doubted reports that we had captured in the nationwide FBI manhunt. >

b. I saw which convict Emma doubted the report that we had captured in the nationwide FBI manhunt. >

c. I saw who Emma doubted the report that we had captured in the nationwide FBI manhunt.

If violations of a given grammar rule, say the CNPC, do not necessarily produce complete unacceptability in languages with overt movement as in (4a), and if the relevant CNP constructions without overt movement exhibit gradient acceptability as in (3), it is not easy to maintain that CNPC effects are explained by grammatical constraints triggered by movement operations. Moreover, we can also ask whether the claim in the syntactic literature can be justified with regard to only $w h$-phrases in overtly moved $w h$-phrases show CNPC

${ }^{2} \mathrm{~A}>\mathrm{B}$ indicates that $\mathrm{A}$ sounds better than $\mathrm{B}$. 
effects, while those in $w h$-in-situ languages do not.

Given these sets of data, this paper aims to explore the following questions which have rarely been asked in the literature on Korean syntax: 1) is it true that $w h$-in-situ questions in Korean do not show CNPC effects? 2) if wh-in-situ questions violating the CNPC in Korean do show variations in acceptability, what is the source of these variations, in other words, the gradient nature of acceptability? 3 ) if there are any factors responsible for gradient acceptability in Korean, are they related in any respect to the already discussed intervening factors for CNPC effects in overt wh-movement languages? and 4) what makes general differences in acceptability of CNP related data between languages with overt wh-movement and those without? To answer these questions, we first examined, through an experimental study of Korean native speakers, if there really exists a wide range of variation in the acceptability of $w h$-in-situ questions violating the CNPC in Korean, as we have suspected, and if so, what kind of factors are responsible for it?

In the experiment, we found our suspicion to be amply verified. We found that the range of acceptability varied widely from quite acceptable to somewhat acceptable to quite unacceptable, as an indication of its gradient nature. We also found that affecting their acceptability are various factors such as distance, semantic complexity, and specificity, which are known to affect the acceptability of overt $w h$-movement questions and also that the effects of these factors are cumulative. We interpret these results showing the processing nature of CNPC effects. According to the processing approach, Island effects arise when the processing load for handling a sentence with a long-distance dependency gets too heavy between the dislocated filler and its gap (Fodor 1983, Frazier \& Clifton 1989, Just \& Carpenter 1992, Kluender \& Kutas 1993, etc). 
This claim, crucially, is based on the fact that the Island effects are gradient and that the acceptability of the questions involving the whmovement is determined by various factors such as distance or referential specificity. The fact that the same is true of $w h$-in-situ questions, i.e., that the acceptability is gradient, and that the same processing factors known to affect the acceptability of overt whmovement questions are also responsible for the variation in acceptability, will lead us to conclude that CNPC effects of wh-insitu in Korean are also processing in nature.

This paper is organized as follows. Section 2 reviews two bifurcated approaches to Island effects, one as a violation of a principle (principles) of competence grammar and the other as a result of processing difficulties. Section 3 introduces an acceptability judgment experiment of $w h$-in-situ questions in Korea violating the CNPC and discusses its results. Section 4 presents factors that affect the acceptability wh-phrases in CNP constructions and discusses that which causes differences between overt wh-movement and wh-insitu with respect to CNP Island effects.

\section{Stories of Islands}

\subsection{A Syntactic Approach}

Since Ross (1967) introduced the term 'Island' to refer to a configuration to block extraction out of it, various proposals have been made regarding ways to capture its definition and its effects. ${ }^{3}$

\footnotetext{
3 Terminology of referring to the association between what and in (i) differs depending on theories. In generative grammar, wh-phrase and its trace form $w h$ -
} 
Over the past 50 years, generative grammar has provided powerful theories that capture Island effects as a part of competence grammar. On the other hand, relatively recent developments on this issue have paid attention to the 'gradient' nature of the effects and attributed detected deviance to the processing cost that depends on the rate of aggregate difficulty.

It was the A-over-A Condition of Chomsky (1962) that first introduced a condition on syntactic application to the syntactic literature to define a domain from which extraction is banned. It states that an element of category such as NP cannot be extracted over the same category NP as in (6).

(5) The A-over-A Condition (Chomsky 1962):

An element of category A cannot be extracted out of a phrase of category A.

(6) * [NP Which puzzle] did you see [NP the mathematician who solved ]?

Pointing out problems of undergeneration in the A-over-A condition, Ross (1967) introduced the term 'Island' describing the phenomena with more specific terminology such as the CNPC

dependency by a syntactic movement. Recent studies on language parsing employ terms such as filler, gap, and filler-gap dependency. Without denoting a specific assumption about the relevant structures and analyses on those, we will use the general term ' $w h$-dependency' to denote an association relation between 'a displaced wh-phrase' and 'its gap/Q-particle' that is required to have a proper interpretation.

(i) what do you think John likes $?$ 
among others. ${ }^{4}$ According to (7), anything that is in a sentence dominated by a NP cannot be moved out of it; in this sense, the CNP is an Island.

(7) Complex NP Constraint (Ross 1967)

No element contained in a sentence dominated by a noun phrase with a lexical head noun may be moved out of that noun phrase by a transformation.

There have been subsequent proposals to deal with the phenomena under the generative grammar framework such as the Subjacency Condition (Chomsky 1973), Barriers (Chomsky 1986) and the Minimal Link Condition (Chomsky 1995), among others. ${ }^{5}$ Though the details of defining syntactic Islands vary, none are free from the prediction that, as far as they are syntactic conditions imposed on

${ }^{4}$ For instance, the A-over-A condition is too strong to rule in the following sentence:

(i) $\left[{ }_{\mathrm{NP}}\right.$ Who] would you approve of $\left[{ }_{\mathrm{NP}}\right.$ my seeing ] ?

${ }^{5}$ Definitions for the relevant conditions are:

(i) Subjacency Condition (Chomsky 1973)

No rule may move a phrase from position $\mathrm{Y}$ to position $\mathrm{X}$ (or conversely) in: $\ldots \mathrm{X} \ldots[\alpha \ldots[\beta \ldots \mathrm{Y} \ldots] \ldots] \ldots \mathrm{X} \ldots$ where and $\beta$ are cyclic nodes.

(ii) Barriers (Chomsky 1973)

(ii-1) $\Upsilon$ is a barrier for $\beta$ if and only if (a) or (b):

a. $\Upsilon$ immediately dominates $\delta, \delta$ a BC for $\beta$ :

b. $\mathbf{Y}$ is a $\mathrm{BC}$ for $\beta, \mathbf{r} \neq \mathrm{IP}$.

(ii-b) $\boldsymbol{Y}$ is a BC(blocking category) for $\beta$ iff $\boldsymbol{\Upsilon}$ is not L-marked and $\boldsymbol{\Upsilon}$ dominates $\beta$.

(iii) The Minimal Link Condition (Chomsky 1995)

$\mathrm{K}$ attracts $\alpha$ only if there is no $\beta, \beta$ closer to $\mathrm{K}$ than $\alpha$, such that $\mathrm{K}$ attracts $\beta$. 
movement operations, they would not allow movement operations at all if the data in question fit in with the given syntactic configurations. However, the acceptability status of the relevant constructions with a syntactic Island is not dichotomous but gradient in nature. ${ }^{6}$ In fact, Chomsky (1973) himself mentioned that there is a gradation of acceptability among sentences with the same grammatical structures. (8b) is worse than (8a) but better than (8c).

(8) a. [NP Who] did you see [NP pictures of __ ]?

b. [NP Who] did you see [NP the pictures of __ $]$ ?

c. [NP Who] did you see [NP John's pictures of __ ]?

Ross (1967) also acknowledged that a wh-question in (9) that fit in with his CNPC configuration indeed sounds better than other CNPC violation sentences such as (6).

(9) [NP How much money] are you making [NP the claim that the company squandered ] ?

Despite such recognition of counterexamples or the data with graded acceptability, purely syntactic approaches to Island effects

6 "Barrier" in Chomsky (1986) addresses to the gradation of acceptability:

(i) $\beta$ is $n$-subjacent to $\alpha$ if and only if there are fewer than $n+1$ barriers for $\beta$ that exclude $\alpha$.

As expressed by ' $n$ ' in $n$-subjacency in (i), theoretically gradient nature seems to be recognized and captured by counting the number of barriers crossed by movement. However, even with the notion of ' $n$-subjacency', Chomsky (1986) restricts the acceptability status to 3 types: 0 -subjacent with perfectly acceptable status, 1-subjacent with marginal status, and anything higher than 1-subjacent with unacceptable status regardless of the value of $n$. However, the different degrees of acceptability status are more diverse than 3 levels. 
have treated them as minor peripheral cases, failing to provide a satisfactory account for them.

\subsection{A Processing Approach}

Providing various data with gradient acceptability, there has been a series of studies done to attribute the degraded nature of the so-called Island effects to accumulated processing difficulty driven above a threshold, which we call the processing approach (Fodor 1983; Kluender 1992, 1998; Hawkins 1999; Sag \& Wasow 1997; Hofmeister \& Sag 2010, etc). According to the processing approach, a dislocated $w h$-phrase itself, which is called filler, is not easy to process from the beginning as its thematic role and grammatical function are not assigned in the dislocated position; hence it needs to be held in the working memory until its gap position is identified. At the same time, being an element without its phonological content, the gap for the dislocated filler is not easily identified. Therefore, a sentence with a filler-gap dependency path itself costs more than one without such paths. Moreover, if there are many intervening elements and complex structures such as Islands to parse between the filler and its gap, processing of all the materials on the path from filler to the gap becomes more costly as processing burdens along the filler-gap path increase (Hawkins 1999, Warren \& Gibson 2005, Hofmeister \& Sag 2010). ${ }^{7}$ Obviously, the processing approach can give explanations on gradient acceptability of given sentences as it assumes that increased processing difficulty lowers the acceptability

\footnotetext{
7 This does not mean certain structural configurations such as CNPs are simply difficult to process. There are several factors that increase processing load of the sentence with CNPC violations such as distance between the filler and its gap and the referential specificity of intervening material etc, which will be discussed in Section 3.
} 
and those factors causing processing difficulty work cumulatively.

For instance, by showing various degrees of acceptability of the following sentences with CNP constructions, Kluender (1992) claims that the gradient nature of CNPC effects shown in (10) can be explained in terms of the cumulative referential processing load of a sentence, which is from violation of the predication principle in $(11):^{8}$

(10) a. This is the paper that we really need to find someone who understands .>

b. This is the paper that we really need to find a linguist who understands .>

c. This is the paper that we really need to find the linguist who understands .>

d. This is the paper that we really need to find his advisor, who understands

e. This is the paper that we really need to find John, who understands

(11) Predication Principle (Kluender 1992: 247)

Initial argument expression NPs must be as referentially specific as possible; all heads and specifiers occurring in complex predicates must be as non-specific in reference as possible.

Because specific/definite NPs contain more lexical information than less specific ones, they demand more cost on processing. Therefore, the more specific an intervening constituent along a filler-

8 The Predication Principle in (11) is from incorporating various proposals about the diverse lexico-semantic and pragmatic factors affecting the well-formedness of long-distance dependencies such as the Dominance Hypothesis of Erteschick-Shir (1977, 1981) and the Topichood Condition proposed by Kuno $(1976,1987)$. 
gap path is, the heavier the processing burden becomes, and therefore more seriously violates the Predication Principle. Increased processing burden leads to lower acceptability judgements (Deane 1991, Warren \& Gibson 2002).

There are other factors involved in processing sentences with CNPC effects according to the processing approach, including distance between the filler and its gap and the complexity of the filler. Regarding the distance factor, Gibson \& Pearlmutter (1998: 265) claim that the greater the distance between an incoming word and the head or dependent to which it attaches, the greater the integration costs. As the filler-gap path becomes longer, it is more difficult to access the memory item because the activation of a mental representation decays overtime. When we apply this factor to the CNPC construction, all other things being equal, wh-interrogatives crossing the CNP boundary are likely to have a longer path than those without any CNP boundary between the filler and its gap. ${ }^{9}$

(12) a. What did John claim that he found in the syntax book? >

b. What did John make the claim that he found in the syntax book?

The complexity of the filler is also relevant in relation to processing costs. Vasishth \& Lewis (2006) claims that semantically richer filler promotes increased acceptability as processing such an element pre-activates the representation it depends on in memory, making it easier to access the representation. The richer the filler is,

9 As Hofmeister \& Sag (2010) mention, the dependency length alone does not cause the unacceptability of Island constructions because sentences with long distance dependency are generally considered acceptable:

(i) Who do you think Bill believes John knows I like ? 
the more easily its reference can be established in mental representation and, accordingly, the better it can be held in working memory. Hofmeister \& Sag (2010) also argue that semantically richer wh-phrases such as which paper in (13a) narrow down the list of candidate answers that have to be considered as opposed to what in (13b), reducing the processing load.

(13) a. Which paper do you really need to find [someone you can intimidate with ]? >

b. What do you really need to find [someone you can intimidate with ]?

(Kluender 1992: 235-236)

In sum, the processing approach provides a better explanation on the gradient nature of CNPC effects, showing that different degrees of acceptability status can be explained in terms of different degrees of processing burden.

\subsection{Island Effects in $W h$-in-situ Languages}

The aforementioned previous literature on Island effects has focused on the gradient nature of the effects with overtly moved phrases. In the purely syntactic approach, the conditions apply to movement operation, preventing an element from escaping from a certain structurally defined environment such as CNPs or more generally Islands. If there is no movement, the given syntactic condition is inoperative. It leads to a prediction that there are no CNPC effects in $w h$-in-situ languages.

There is a school of thought claiming that there are certain, somewhat covert types of in-situ-wh-phrase movement operations at 
LF. For instance, according to Huang (1982) who first extended the movement approach of this sort to wh-in-situ in languages like Chinese, a wh-in-situ phrase does undergo movement in order to receive a proper interpretation at LF, but it is predicted not to show any Island effects. This is because the LF movement, unlike the Sstructure movement, is not subject to the locality restrictions such as subjacency. Alternatively, there has been a group of scholars who argued that $w h$-questions in $w h$-in-situ languages are interpreted in a completely different manner. Their interpretations come from unselective binding of $w h$-phrases by Q(or the Q-particle), which checks the Q feature in C (Li 1992, Aoun \& Li 1993, Tsai 1994, Cole \& Hermon 1998, etc.). ${ }^{10}$ Since unselective binding is not a movement operation, Island effects are not expected in this approach either. In fact, when it comes to the Island effects of in-situ $w h$-phrases, the focus of research in the syntactic literature has been given to explaining the differences in various types of Island effects, so-called selective Island effects. For instance, wh-in-situ phrases in Korean and Japanese do show wh-Island effects although they do not show Complex NP Island effects and Adjunct Island effects. ${ }^{11}$ The covert

10 According to the unselective binding approach, wh-phrases are assumed to be indefinite pronouns without any quantificational forces.

${ }^{11}$ Huang's proposal as well as an unselective binding analysis, however, cannot explain the selective Island effects in Korean and Japanese, i.e., the fact that, and various proposals have been made to explain the difference between Chinese-type and Korean-type wh-in-situ languages (Nishigauchi 1986, Choe 1987, Li 1992, Aoun \& Li 1993, Tsai 1994, Cole \& Hermon 1998, etc.). For instance, according to Tsai (1994), there are different positions for Q depending on languages. In Chinese, $\mathrm{Q}$ is generated in the specifier position of $\mathrm{CP}$ and there it binds in-situwh phrases. This type of unselective binding is free from locality restrictions. Q, which requires movement for checking Q-feature of $\mathrm{C}$ is sensitive to the locality restriction but in Chinese, since $\mathrm{Q}$ is generated in the spec of $\mathrm{CP}$, there is no need for Q to move. In the case of Korean and Japanese, however, Q is generated in the Spec of DP/PP, but not in the Spec of CP. Therefore, depending on the types of Islands, there will be a different effect: 
pied-piping approach of Nishigauchi (1986), based on feature percolation, can distinguish the former from the latter such that the wh-phrase percolates its feature all the way to the head noun of CNPs, while it cannot do so in $w h$-Islands. Hence the pied-piped CNP itself moves covertly without violating Island constraints in CNP constructions. On the other hand, wh-features cannot be percolated up to the embedded $w h$-Islands due to the embedded $\mathrm{C}$ with $\mathrm{Q}$ feature. ${ }^{12}$ In Chinese, however, there are no Island effects at all regardless of types of Islands including $w h$-Islands.

What needs to be noted here is that, as far as strong Islands such as CNP Islands are concerned, it has been agreed that $w h$-in-situ languages do not show Island effects as discussed. In addition, not much attention has been given to the gradient nature of the $w h$-Island effects of $w h$-in-situ if there are any.

In the processing approach, processing burden is calculated based on filler-gap dependency links measuring factors that cause processing difficulties such as the distance between the filler and its gap (or length of the filler-gap path), complexity of the filler phrases, and specificity of intervening elements between the filler and its gap. If there is no overt movement, there will be neither fillers nor gaps. Unless we assume the existence of other dependency links that

(i) ${ }_{\mathrm{DP}} \mathbf{Q}\left[{ }_{\mathrm{CP}}\right.$ nwukwu-ka ssu-n] chayk]-i eps-e-ci-ess-ni? who-Nom write-Comp book-Nom disappear-Past-QE

'Who is the person $\mathrm{x}$ such that the book which $\mathrm{x}$ wrote disappeared?'

(ii) ??Ne-nun $\quad\left[\right.$ сP Yenghi-ka [ ${ }_{\text {DP }} \mathbf{Q}$ [mwues]]-ul sa-ess-nunci] al-ko sip-ni? You-Top Yenghi-Nom what-Acc buy-Past-QE know-Comp want-QE 'What is the thing $\mathrm{x}$ such that you want to know whether Yenghi bought $\mathrm{x}$ ?'

12 Since these proposals are not directly relevant to our research question and/or the claim we will make in this paper, we will not discuss them here. Interested readers are referred to Yoon (2006). 
behave similarly to the filler-gap path, i.e., unless there is some other source of processing loads in $w h$-in-situ questions, $w h$-in-situ will not show CNPC effects.

In what follows, we report results of an experiment to investigate how CNPC effects-related data are judged by native Korean speakers and what are the relevant factors responsible for the different judgments.

\section{Gradience in the Acceptability of Korean Wh-in-situ Questions with a CNPC Violation}

\subsection{Participants}

Thirty four undergraduates at Sejong University in Seoul, Korea participated in the experiment for course credit. All were native speakers of Korean studying English language and literature. They were taking an introduction course in English linguistics but none were aware of syntactic Island constraints.

\subsection{Materials and Design}

The experiment was designed to investigate whether or not there are any CNPC effects in Korean, and what causes the effects, if any. Based on the claims of the processing approaches to the CNPC effects in overt $w h$-movement, three factors - i.e., distance between a wh-phrase and the $\mathrm{Q}$ (uestion) particle, specificity of the head noun of CNPs, and semantic complexity of in-situ wh-phrase (D-linking) - are tested with respect to their effects on CNPC violations. If $w h-$ 
in-situ languages such as Korean do show CNPC effects, and there is gradience the in acceptability status of in-situ $w h$-interrogatives in CNPs, it will be worthy to check whether the factors responsible for the variations in the CNPC Effects in Korean are the same as those in overt wh-movement languages. Given that processing of $w h$-in-situ questions will be different from that of overt $w h$-movement questions, we expect that manipulating these factors in $w h$-in-situ questions in Korean should yield a processing burden distinct from that in overt wh-movement languages and accordingly that it will result in different acceptability status of the sentences in question. To be specific, our predictions are that there are variations in the acceptability status in $w h$-in-situ questions with CNPC violations in Korean and that the same factors responsible for processing filler-gap dependency in overt $w h$-movement will affect processing of $w h$-insitu questions.

Sentences with a CNPC violation and those without it were tested for their acceptability in this experiment. As for the sentences with a CNPC violation, there were five patterns tested in the experiments, which varied with respect to the content of the wh-phrases (CNPs with $\mathrm{D}$ (iscourse)-linked $w h$-phrases), the properties of head NPs (head nouns of CNPs with specificity), the distance between the filler and its gap (three clausal boundaries between wh-phrases and Qparticles), CNPs with both a specificity factor and a distance factor, and those with none of these three factors (basic CNPs). Sample experimental items of the five patterns are illustrated in (15).

(14) a. Baseline

Ne-nun [John-i mwues-ul sa-ssta]-ko sayngkakha-ni? you-Top [John-Nom what-Acc buy-Past]-Comp think-Q (lit.) 'You think John bought what?' 
98 A Processing Approach to Complex NP Island Effects in Korean

(15) a. Basic CNP

Ne-nun [[nwuka kaci-ko iss]-nun kulim]-i yoksimna-ni?

you-Top [[who have be]-Rel picture]-Nom want to have-Q

(lit.) 'You want to have [a picture [that who has]]?'

b. D-linking

Ne-nun [[etten ilon-ul yenkwuha]-nun salam]-ul chacka-ss-ni?

You-Top [[which theory-Acc research]-Rel person]-Acc went to see-Q

(lit.) 'You go to see [a person [who are working on which theory]]?'

c. Specificity

Ne-nun [[nwuka kaci-ko iss]-nun ku kulim]-i yoksimna-ni? you-Top [[who-Acc have be]-Rel that picture]-Nom want to have-Q (lit.) 'You want to have [the picture [that who has]]?'

d. Distance

Ne-nun [[[nwuka manna]-n haksayngtul]-i

you-Top [[[who-Nom meet]-Rel students]-Nom

ttokttokhata]-ko sayngkakha-ni?

smart]-Comp think-Q

(lit.) 'You think [[students [who met $]]$ is smart $]$ ?'

e. Distance and Specificity

Ne-nun [[[nwuka manna]-n 1haknyen 3pan haksayngtul]-i

you-Top [who-Nom meet-Rel 1st grade group3 students-Nom ttokttokhata]-ko sayngkakha-ni?

smart-Comp think-Q

(lit.) 'You think [[1st grade group 3 students [who met]] is smart]?' 
All items were pseudo-randomized so that the related factors did not appear consecutively. An acceptability rating task was presented as a paper survey. Yes-no questions, ungrammatical (case-markerwise) interrogatives and declaratives with comparable sentence length were added to the survey list so that the participants did not know what the target patterns were. The task was a 5-point scale acceptability judgement task where 1 represented "least acceptable" and 5 represented "most acceptable". Participants were under no time constraints during the survey.

\subsection{Results and Discussions}

Each participant's ratings were transformed to a percentile scale. The results show that acceptability ratings of sentences with in-situ wh-phrases in CNPs vary widely depending on factors that affect the processing complexity of $w h$-phrases in Islands.

The mean of the acceptability judgments of the tested sentences are shown in Table 1 with a percentile scale:

Table 1. Descriptive Statistics for Processing Factors

\begin{tabular}{lll}
\hline \hline Factors & Mean & $S D$ \\
\hline Baseline & 92.2 & 13.38 \\
Basic CNP & 76.2 & 24.67 \\
D-Linking (of in-situ $w h$-phrases) & 76.9 & 18.17 \\
Specificity (of head nouns) & 27.7 & 17.68 \\
Distance (between $w h$-phrase and Q-particle) & 48.4 & 22.76 \\
\hline
\end{tabular}

Table 1 displays descriptive statistics for students' acceptability on the sentences with three processing factors such as base Islands, dlinking, specificity, and distance. Average acceptability was 
computed for the items that measure the same processing factors. Baseline sentences without CNP Islands were considered as a reference. In order to see the effects of the processing factors on acceptability levels, repeated measures ANOVA was conducted using SPSS 18.0. Findings indicate that the effects were significantly different $(\mathrm{F}=53.451, \mathrm{df}=4,124, \mathrm{p}<0.001)$. This indicates that students' acceptability level was different according to the processing factors that the sentences contain. Post-hoc analyses showed that the difference was attributed to all the paired comparisons except for Basic CNP vs. D-linking factors. In other words, the acceptability level was significantly different at $\alpha_{2}=0.05$ for all the pairs except for Basic CNP vs D-linking.

The results of the experiment showed that the acceptability of the $w h$-in-situ questions violating the CNPC in Korean varies widely, from the lowest test sentence with a value of $24.2 \%$ to the highest sentence at $82.8 \%$. As indicated in Figure 1 with mean percentile values for each set, a canonical CNPC violation example employed to show the lack of the CNPC effects in wh-in-situ languages was rated relatively high $(76.2 \%$ as their mean value) but lower than sentences without any Island constraint violation $(92.2 \%$ mean value). 
Figure 1. Mean Percentile Values of CNPC violations and Baseline

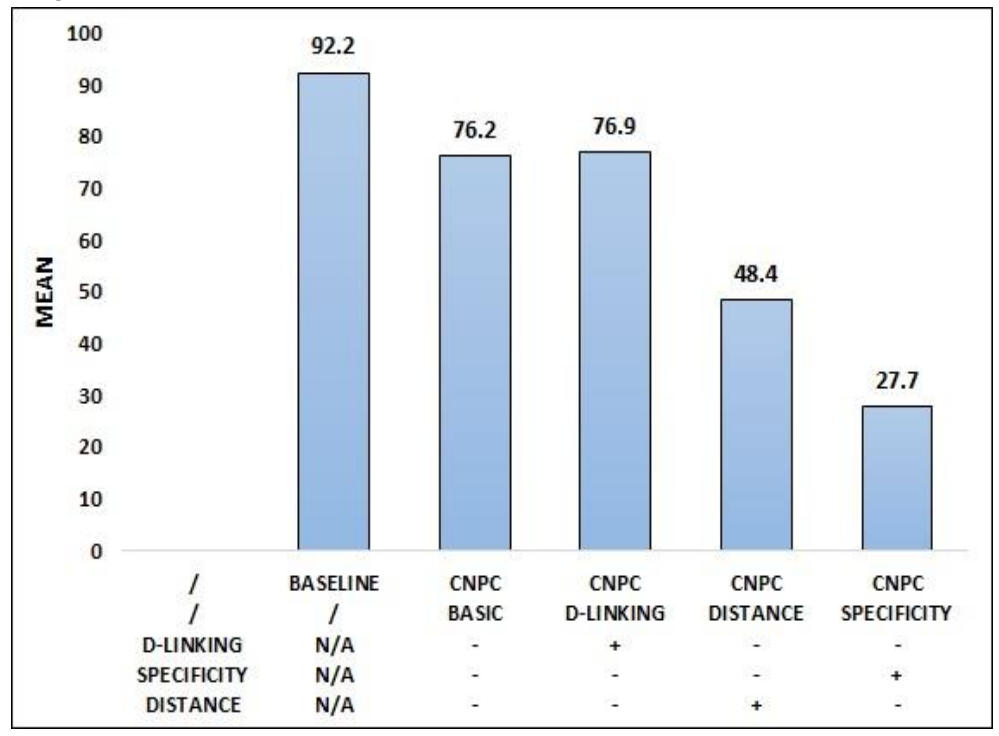

The basic CNP sentences received higher ratings than other CNP sentences with specificity effects and the distance factor added to the Islands; the specificity of the head noun and distance between whphrases and Q-particles degraded acceptability. More specifically, the acceptability scale dropped from $76.2 \%$ to $48.4 \%$ when the whphrase was deeply embedded such that the distance between the whphrase and Q-particle at the end of the sentence became larger, indicating that increasing dependency distance reduces acceptability. When the head of the CNP is specific, the acceptability dropped drastically from $76.2 \%$ to $27.7 \%$, showing that when processing of the intervening constituent (in our case, the head noun of the CNP) consumes more resources by being definite, the acceptability is degraded. In general, definite NPs refer to established referents in the discourse, triggering a search for their referents. Hence, in order to 
parse, extra processing cost needs to be paid compared to that of indefinite NPs.

As for the effects of D-linking, some rather surprising results were found in the comparisons between basic CNP sentences and CNP sentences with D-linked wh-phrases. Contrary to our expectation, there was only a minor increase in acceptability status when the whphrase was D-linked from $76.2 \%$ to $76.9 \%$. At the moment, there is no clear explanation for this.

When factors that affect the processing load are cumulated, the acceptability is worsened as expected. Figure 2 shows the cumulative effects of processing factors. When the wh-phrase is deeply embedded and the head noun of the CNP is specific, the sentence received the lowest score for its acceptability (24.2\%).

Figure 2. Cumulative Effects of Processing Factors

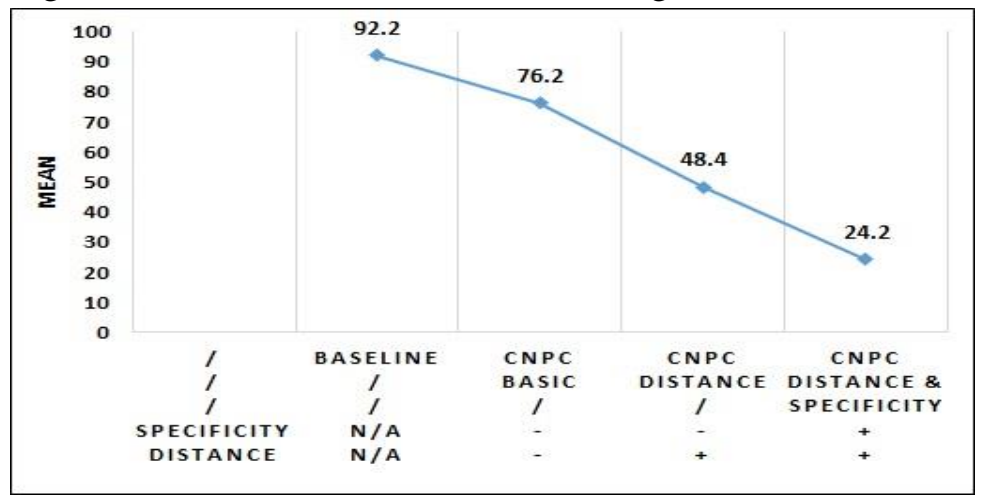

Recall that there were research questions raised in this paper with respect to CNPC effects in Korean. The result of the experiment, first of all, verifies our impression about CNPC effects of Korean wh-insitu questions: not all $w h$-in-situ questions in the CNP configurations in Korean are equally acceptable, rejecting the claim that there are no 
CNPC effects at all in Korean where wh-phrases do not have to move overtly. The ensuing question is as follows: if there is degraded acceptability of $w h$-in-situ questions violating the CNPC in Korean, to what does this gradient nature owe its character? The results of the experiment indicate that distance between the $w h$-phrases and the $\mathrm{Q}$ particle responsible for its interrogative interpretations matters. In addition, the properties of the head noun located between the whphrase and the Q particle affect the acceptability; the specificity of an intervening NP incurs more processing costs, thereby degrading the acceptability.

To summarize, the results of our experiment show that the factors responsible for gradient acceptability in $w h$-in-situ questions violating the CNPC in Korean are almost the same as those previously identified for the comparable sentences in overt $w h$ movement languages. The only difference found in the current experiment is that, in languages with overt $w h$-movement, semantic complexity of the filler (D-linking) does increase the acceptability of CNPC violated sentences, while in Korean, the D-linking effects were somewhat trivial.

\section{Concluding Remarks: Differences in CNPC Effects Between Overt Wh-movement Questions and Wh-in-situ Questions}

The standard assumption about CNPC effects is that overt whmovement questions show the effects while $w h$-in-situ questions do not, and explaining this difference has been one of the muchdiscussed issues in the theory of movement. Contrary to the previous claim based on movement theories, we have shown that the 
acceptability of $w h$-questions violating the CNPC shows a wide range of variations not only in overt wh-movement languages but also in $w h$-in-situ languages. This implies that in both types of languages, processing costs affect the acceptability status of the sentences with CNP configurations. We have seen that the cost is cumulative and the results become worse if more factors causing processing difficulty are involved.

This explanation, in turn, leads us to the original question stated at the outset of this paper: why the standard syntactic assumption about the CNP Island effects of $w h$-in-situ in Korean is that they do not show CNPC effects, unlike the overtly moved wh-phrases in languages such as English. In overt wh-movement languages, the filler is dislocated and there is an empty gap that needs to be identified. The dislocated $w h$-phrase, whose thematic role and grammatical function are unassigned, must be held in the working memory until the gap is identified, and this process, naturally, will increase the processing load of a sentence with a filler-gap dependency. Processing loads incurred by wh-in-situ questions in Korean will be lower. This is because the dependency here is not the filler-gap dependency, but rather the semantic linking between the wh-phrase and the $\mathrm{Q}$ particle. Given that much of the processing loads for overt $w h$-movement questions come from holding the filler in working memory, we can surmise that processing loads will be lower in $w h$-in-situ questions. We suggest that this difference in the cumulative processing loads between overt $w h$-movement questions and $w h$-in-situ questions is translated into the presence or absence of CNPC effects in two types of movement languages. 


\section{References}

Aoun, J. \& Y.-H. Li. 1993. On Some Differences Between Chinese and Japanese. Linguistic Inquiry 24, 365-372.

Cheng, L. 1991. On the Typology of Wh-Questions. Ph.D Dissertation. MIT.

Choe, J.-W. 1987. LF Movement and Pied-Piping. Linguistic Inquiry $18,348-353$.

Chomsky, N. 1962. A Transformational Approach to Syntax. New York: Prentice-Hall.

. 1973. Conditions on Transformations. In S. Anderson \& P. Kiparsky (eds.), A Festschrift for Morris Halle 232-286. New York: Holt, Rinehart \& Winston. 1986. Barriers. Cambridge, MA: MIT press. . 1995. The Minimalist Program. Cambridge, MA: MIT Press.

Cole, P. \& G. Hermon. 1998. The Typology of WH Movement: WH Questions in Malay. Syntax 1, 221-258.

Deane, P. 1991. A Cognitive Theory of Island Phenomena. Cognitive Linguistics 2, 1-63.

Erteschick-Shir, N. 1977. On the Nature of Island Constraints. Bloomington, IN: Indiana University Linguistics Club. . 1981. More on Extractability from Quasi-NPs. Linguistic Inquiry 12, 665-670.

Fodor, J. 1983. Phrase Structure Parsing and the Island Constraints. Linguistics \& Philosopy 6, 163-223.

Frazier, L. \& C. Clifton. 1989. Successive Cyclicty in the Grammar and the Parser. Language \& Cognitive Processes 4, 93-126.

Gibson, E. \& N. Pearlmutter. 1998. Constraints on Sentence Comprehension. Trends in Cognitive Sciences 2.7, 262-268. 
106 A Processing Approach to Complex NP Island Effects in Korean

Hawkins, J. 1999. Processing Complexity and Filler-Gap Dependencies across Grammars. Language 75.2, 244-285.

Hofmeister, P. \& I. Sag. 2010. Cognitive Constraints and Island Effects. Language 86, 366-415.

Huang, C.-T. 1982. Logical Relations in Chinese and the Theory of Grammar. Ph.D Dissertation. MIT.

Just, M. \& P. Carpenter. 1992. A Capacity Theory of Comprehension: Individual Differences in Working Memory. Psychological Review 99, 122-149.

Kluender, R. 1992. Deriving Islands Constraints from Principles of Predication. In H. Goodluck \& M. Rochemont (eds.), Island Constraints: Theory, Acquisition \& Processing 223-258. Dordrecht: Kluwer. . 1998. On the Distinction Between Strong and Weak Islands: A Processing Perspective. In P. Culicover \& L. McNally (eds.), Syntax and Semantics 29: The Limits of Syntax 241-279. San Diego, CA: Academic Press.

Kluender, R. \& M. Kutas. 1993. Subjacency as a Processing

Phenomenon. Language \& Cognitive Processes 8, 573-633.

Kuno, S. 1976. Subject, Theme, and the Speaker's Empathy: A Reexamination of Relativization Phenomena. In C. Li (ed.), Subject and Topic 418-444. New York: Academic Press. . 1987. Funcitonal Syntax. Chicago, IL: University of Chicago Press.

Li, Y. 1992. Indefinite Wh in Mandarin Chinese. Journal of East Asian Linguistics 1, 125-155.

Nishigauchi, T. 1986. Quantification in Syntax. Ph.D Dissertation. MIT.

1992. Construing Wh. In J. Huang \& R. May (eds.), Studies in Linguistics and Philosophy: Logical Structure and 
Linguistic Structure 197-232. Dordrecht/Boston/London: Kluwer Academic Publishers.

Ross, J. 1967. Constraints on Variables in Syntax. Ph.D Dissertation. MIT.

Sag, I. \& T. Wasow. 1997. Syntactic Theory: A Formal Introduction. Ms. Stanford University.

Suh, C.-M. 1989. WH-Constructions in Korean. Harvard Studies in Korean Linguistics 3, 517-526.

Tsai, W.-T. 1994. On Economizing the Theory of A-Bar Dependencies. Ph.D Dissertation. MIT.

Vasishth, S. \& R. Lewis. 2006. Argument-Head Distance and Processing Complexity: Explaining both Locality and Antilocality Effects. Language 82.4, 767-794.

Warren, T. \& E. Gibson. 2002. The Influence of Referential Processing on Sentence Complexity. Cognition 85.1, 79-112. . 2005. Effects of NP Type in Reading Cleft Sentences in

English. Language \& Cognitive Processes 20.6, 751-767.

Watanabe, A. 1992. Subjacency and S-Structure Movement of Whin-situ. Journal of East Asian Linguistics 1, 255-291.

Yoon, J.-M. 1999. Decomposing Wh-Questions: Wh-Marking and Wh-Scoping Movement. Studies in Generative Grammar 9.1, 153-198.

2006. Selective Island Effects in Korean WhConstructions: A Diachronic Approach. Korean Journal of Linguistics 31.2, 165-204. 